\title{
Calcium Signaling in Single Peripheral Sensory Nerve Terminals
}

\author{
Tony D. Gover, ${ }^{1}$ Joseph P. Y. Kao, ${ }^{1,2,3}$ and Daniel Weinreich ${ }^{1,4}$ \\ ${ }^{1}$ The Neuroscience Program, University of Maryland, ${ }^{2}$ Medical Biotechnology Center, University of Maryland Biotechnology Institute, and Departments of \\ ${ }^{3}$ Physiology and 4 Pharmacology and Experimental Therapeutics, University of Maryland, School of Medicine, Baltimore, Maryland 21201-1559
}

\begin{abstract}
Peripheral sensory nerve terminals (PSNTs) have a dual function: reporting normal and abnormal sensations and releasing trophic factors to maintain the structure and function of epithelial cells. Although it is widely considered that intracellular $\mathrm{Ca}^{2+}$ plays a critical signaling role for both functions, the role of $\mathrm{Ca}^{2+}$ signaling has never been studied in PSNTs, primarily because of their small size and anatomical inaccessibility. Here, using epifluoresence microscopy and a fluorescent $\mathrm{Ca}^{2+}$ indicator, we report that action potentials or chemical irritation can elicit transient rises in $\left[\mathrm{Ca}^{2+}\right]_{\mathrm{i}}\left(\mathrm{Ca}^{2+}\right.$ transients) in PSNTs within the corneal epithelium of the rat. In vitro electrical stimulation of the ciliary nerves in the eye, or electrical field stimulation of the cornea, evoked $\mathrm{Ca}^{2+}$ transients with a magnitude that was proportional to the number of stimuli applied over the range of $1-10$ stimuli. $\mathrm{Ca}^{2+}$ transients were significantly blocked by 1 mM lidocaine, $4.1 \mu \mathrm{m}$ saxitoxin (STX), or L-type $\mathrm{Ca}^{2+}$ channel antagonists ( $1 \mathrm{~mm}$ diltiazem or $20 \mu \mathrm{m}$ nifedipine). The nociceptive agonist capsaicin $(1 \mu \mathrm{M})$ elicited $\mathrm{Ca}^{2+}$ transients in all nerve terminals studied. Capsaicin-evoked $\mathrm{Ca}^{2+}$ transients were completely blocked by the vanilloid receptor 1 antagonist capsazepine $(100 \mu \mathrm{M})$. In contrast, capsaicin-evoked $\mathrm{Ca}^{2+}$ transients were not attenuated by preincubation with $4.1 \mu \mathrm{m}$ STX or $20 \mu \mathrm{m}$ nifedipine. These findings demonstrate, for the first time, that nerve impulses or chemical stimulation promote $\mathrm{Ca}^{2+}$ entry into PSNTs, including nociceptors.
\end{abstract}

Key words: trigeminal primary afferents; eye; cornea; nociceptors; calcium; capsaicin

\section{Introduction}

Detection of noxious and nonnoxious stimuli in peripheral organs is initiated by the activation of peripheral sensory nerve terminals (PSNTs). PSNTs are endowed with specialized receptors that transduce thermal, mechanical, and chemical stimuli into electrical potentials that may generate action potentials in the parent axons. Through propagated action potentials, the parent axons communicate the modalities and intensity of stimuli to the CNS. Sensory afferent neurons, however, are not simply passive conduits that relay information from the periphery to the CNS. These neurons exhibit various forms of plasticity, including sensitization and desensitization, and they can release neurotransmitters and neurotrophic factors into surrounding tissues. Released neuropeptides, such as substance P (SP) or calcitonin gene-related peptide (CGRP), can function as trophic factors that support growth and differentiation in neighboring epithelial cells (for review, see Belmonte and Gallar, 1996). These same neuropeptides can initiate neurogenic inflammation-degranulation of mast cells, vasodilation, edema, and other inflammatory reactions (for review, see Maggi, 1991). It is presumed that these and

Received Dec. 9, 2002; revised April 1, 2003; accepted April 3, 2003.

This work was supported by National Institutes of Health Grants NS-22069 and GM-56481 (to D.W. and J.P.Y.K., respectively). We thank Drs. Michael Gold and Jon Lederer for helpful discussions and for reviewing a previous version of this manuscript, and Dr. Darrin Brager for generous assistance with presentation graphics. We also thank Dr. Eun Joo Oh for continual support on this project and artwork for Figure 1.

Correspondence should be addressed to Dr. Daniel Weinreich, Department of Pharmacology and Experimental Therapeutics, University of Maryland, School of Medicine, Bressler Research Building, Room 4-002, 655 West Baltimore Street, Baltimore, MD 21201-1559. E-mail: dweinrei@umaryland.edu.

Copyright $\odot 2003$ Society for Neuroscience $\quad$ 0270-6474/03/234793-05\$15.00/0 other functions are supported by changes in intracellular free $\mathrm{Ca}^{2+}$ concentration $\left(\left[\mathrm{Ca}^{2+}\right]_{\mathrm{i}}\right)$ within PSNTs.

Measurement of membrane currents or $\left[\mathrm{Ca}^{2+}\right]_{\mathrm{i}}$ in individual PSNTs has not been reported, because they are small (0.25-1.5 $\mu \mathrm{m}$ in diameter) (Whitear, 1960) and are almost invariably deeply embedded within tissue (e.g., nerve terminals in skin, joints, and bladder). Consequently, $\mathrm{Ca}^{2+}$ signaling in PSNTs remains completely unexplored. The cornea is an exceptional preparation for studying $\mathrm{Ca}^{2+}$ dynamics in PSNTs. The cornea is transparent and has the greatest density of peripheral sensory nerve innervation of any tissue. Nerve terminals in the cornea are almost exclusively nociceptive $\mathrm{A} \delta$ and $\mathrm{C}$ fibers originating from the ophthalmic branch of the trigeminal ganglion (Marfurt, 2000). The sensory nerve terminals of the cornea are all free nerve endings in the epithelium (Fig. 1), and they often approach within a few micrometers of the surface (Zander and Weddell, 1951; MacIver and Tanelian, 1993). In this study, we report, for the first time, $\mathrm{Ca}^{2+}$ signals measured in individual PSNTs of the rat cornea resulting from action potential activity or chemical stimulation.

\section{Materials and Methods}

Fluorescent dye loading and tissue dissection. Experiments were performed on the whole eye or isolated cornea from male Sprague Dawley rats (140-300 gm). One microliter of a solution containing $0.9 \% \mathrm{w} / \mathrm{v} \mathrm{NaCl}$, $20 \%$ w/v Oregon Green 488 BAPTA-1 dextran (OGB-1 dextran) (10 $\mathrm{kDa}$; Molecular Probes, Eugene, OR) or 10\% w/v tetramethylrhodamine dextran (10 kDa; Molecular Probes), and 1-2\% v/v Triton X-100 (Sigma, St. Louis, MO) was deposited on each cornea of a ketamine-anesthetized 


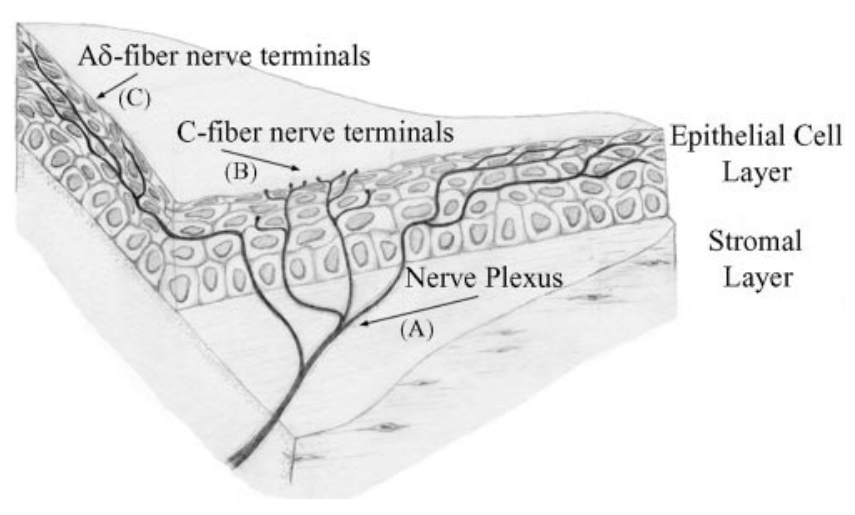

Figure 1. Illustration of the branching pattern of $A \delta$ and $C$ fiber nerve terminals within the cornea. $A \delta$ and C fibers course together in the collagenous stromal layer. The nerve plexus in the stromal layer consists of extensively branching $A \delta$ and $C$ fibers. The fibers separate as they turn toward the superficial epithelial layers, where they terminate. Letters in parentheses correspond to the images in Figure 2. Adapted from Maclver and Tanelian (1993).

animal for $1 \mathrm{~min}$. After dye exposure, the eyes were rinsed with $\mathrm{Ca}^{2+}$ and $\mathrm{Mg}^{2+}$-free PBS. Rats were killed $16-60 \mathrm{hr}$ later by pentobarbital (100 mg/kg, i.p.). For experiments with intact eyeballs, eyes were dissected along with a portion of the ciliary nerves that contain the afferent axons projecting from the trigeminal ganglion to the cornea. External ocular muscles were removed to minimize movement artifacts during electrical stimulation. For experiments on isolated corneas, corneas were dissected directly from the animal immediately after death. Eyeballs and isolated corneas were maintained in an oxygenated Locke solution containing (in mM): 10 glucose, $136 \mathrm{NaCl}, 5.6 \mathrm{KCl}, 1.2 \mathrm{NaH}_{2} \mathrm{PO}_{4}, 14.3$ $\mathrm{NaHCO}_{3}, 1.2 \mathrm{MgCl}_{2}$, and $2.2 \mathrm{CaCl}_{2}, \mathrm{pH}$ 7.4. Animal procedures were approved by the Institutional Animal Care and Use Committee of the University of Maryland, Baltimore.

Electrical and chemical stimulation. Corneal nerve terminals (CNTs) were activated by antidromic action potentials evoked by a suction electrode or by electric field stimulation with platinum electrodes placed in the recording chamber. For antidromic stimulation, the optic nerve and surrounding nerves, including those housing sensory afferents, were drawn into a suction electrode. Electrical stimuli were generated by a stimulator and delivered through a stimulus isolation unit (both from Astro-Med, West Warwick, RI). The applied stimulation voltage was greater than threshold to ensure consistent neuron activation $(1 \mathrm{msec}$, $50-60 \mathrm{~V}$ for suction electrode; $1 \mathrm{msec}, 150 \mathrm{~V}$ for field stimulation). The eyeball or cornea was continuously perfused with oxygenated Locke solution at room temperature $\left(22-24^{\circ} \mathrm{C}\right)$. To minimize movement, whole eyeballs were pinned to the bottom of the recording chamber, which was lined with dental wax. Corneal sections were immobilized by using a U-shaped harp constructed of stainless-steel wire (2 $\mathrm{mm}$ in diameter). The strings of the harp, which were spaced $\sim 1 \mathrm{~mm}$ apart, were either lycra or nylon threads. The stability of the corneal sections was assessed by switching between different reservoirs of Locke solution. During these maneuvers, the values of the fractional change in fluorescence intensity relative to baseline $\left(\Delta F / F_{0}\right)$ remained steady, indicating that the corneal sections were adequately immobilized. For experiments that tested the effects of antagonists, the eyeball or isolated cornea was perfused with the antagonists, at concentrations that were consistent with published studies on the cornea (Belmonte and Gallar, 1996), for at least 20 min to allow penetration of drugs to CNTs. When capsaicin was used, the drug was applied via a capillary positioned $2 \mathrm{~mm}$ from the corneal surface. Confocal microscopical imaging of nerve fibers labeled with tetramethylrhodamine dextran was performed on an inverted microscope with a $40 \times$ water-immersion objective (Axiovert, LSM 410; Zeiss, Jena, Germany). Corneal sections were excited at $568 \mathrm{~nm}$, and fluorescence emission was passed through a $590 \mathrm{~nm}$ long-pass filter before photometric detection.

Calcium imaging. Calcium imaging was performed on an upright epifluorescence microscope (Laborlux 12; Leitz, Wetzlar, Germany) with a water-immersion objective (63×; 0.95 numerical aperture; Zeiss). Tissues were excited by the output of a $100 \mathrm{~W}$ mercury arc lamp (Opti-Quip,
Highland Mills, NY) that passed through a $480 \mathrm{~nm}$ bandpass filter [30 $\mathrm{nm}$, full width at half maximum (FWHM)]. Fluorescence emission was passed through a $535 \mathrm{~nm}$ bandpass filter (40 nm, FWHM) before being captured with a cooled CCD camera (CoolSnap HQ; Roper Scientific, Tucson, AZ). Excitation exposure was controlled by an electromechanical shutter (Uniblitz; Vincent Associates, Rochester, NY) gated by transistor-transistor logic (TTL) pulses. Metafluor software (Universal Imaging, Dowingtown, PA) was used for image acquisition and instrument control.

Analysis. OGB-1 dextran measurements are reported as the fractional change in fluorescence intensity relative to baseline $\left(\Delta F / F_{0}\right)$, which was determined as follows. Within a temporal sequence of fluorescence images, a region of interest (ROI) was drawn around a portion of each CNT to be analyzed. The fluorescence signal from each terminal was calculated as the pixel-averaged intensity within each ROI. The precise boundary of each ROI enclosing a terminal was replicated and placed over an adjacent region of the image that was devoid of nerve processes. The pixelaveraged intensity from each of these ROIs was taken as background and was subtracted from the fluorescence signal obtained for the corresponding nerve terminal to yield the background-corrected fluorescence signal $(F)$ from that terminal. In electrical stimulation experiments, in which sequences of images were acquired over short time intervals, the baseline fluorescence $\left(F_{0}\right)$ for each terminal was calculated as the fluorescence signal of the terminal averaged over the three to four frames immediately preceding the onset of the stimulus. The difference between the fluorescence signal and the baseline $\left(\Delta F=F-F_{0}\right)$ at each time point was ratioed against the baseline value to yield $\Delta F / F_{0}$. In experiments in which stimulation was achieved pharmacologically and sequences of images were acquired over extended time periods, we typically observed a slight downward drift in baseline, which was principally attributable to photobleaching of the indicator. In such cases, as expected, the drift was always well fit by a low-amplitude single-exponential decay. The fitted baseline value $\left(F_{0}\right)$ at every time point was then used to calculate $\Delta F / F_{0}$. The amplitudes of $\mathrm{Ca}^{2+}$ transients were determined from $\Delta F / F_{0}$ traces that were smoothed by three-point adjacent averaging. All of the $\Delta F / F_{0}$ values given are means \pm SEM. For channel antagonist experiments, significance was determined by paired or independent $t$ test, as appropriate. A value of $p<0.05$ was considered significant.

\section{Results}

One to $3 \mathrm{~d}$ after loading corneas with dextran-conjugated fluorophores in vivo, nerve bundles in the stroma and free CNTs in the epithelium could be easily visualized in vitro by confocal or epifluorescence microscopy. As illustrated in Figure 2, nerves in all layers of the cornea were labeled: subepithelial branches lying deep within the stroma (Fig. 2A); families of thin axons that travel together in the basal epithelium (so-called leashes) (Fig. $2 C$ ); and terminal nerve endings lying a few micrometers beneath the surface of the outermost epithelial cells (Fig. 2 B). These anatomical features of nerves and nerve terminals (Fig. 1) seen after our loading procedure are consistent with previous morphological studies using methylene blue staining (Zander and Weddell, 1951), gold impregnation (Rozsa and Beuerman, 1982), fluorescent labeling (Harris and Purves, 1989; MacIver and Tanelian, 1993), and immunocytochemistry (Jones and Marfurt, 1998). Corneal nerve fibers loaded with either tetramethylrhodamine dextran or with the $\mathrm{Ca}^{2+}$ indicator OGB-1 dextran showed no obvious morphological differences.

Action potentials can be recorded extracellularly from single CNTs in the surface epithelium after electrical stimulation of the ciliary nerves that contain corneal afferent axons (Brock et al., 1998). The occurrence of action potentials and the presumed necessity of $\mathrm{Ca}^{2+}$ in CNTs suggest that voltage-dependent calcium channels (VDCCs) might be expressed in CNTs. We first tested whether action potentials in CNTs can trigger a transient rise in $\left[\mathrm{Ca}^{2+}\right]_{\mathrm{i}}$ (i.e., a $\mathrm{Ca}^{2+}$ transient). CNTs were loaded with 

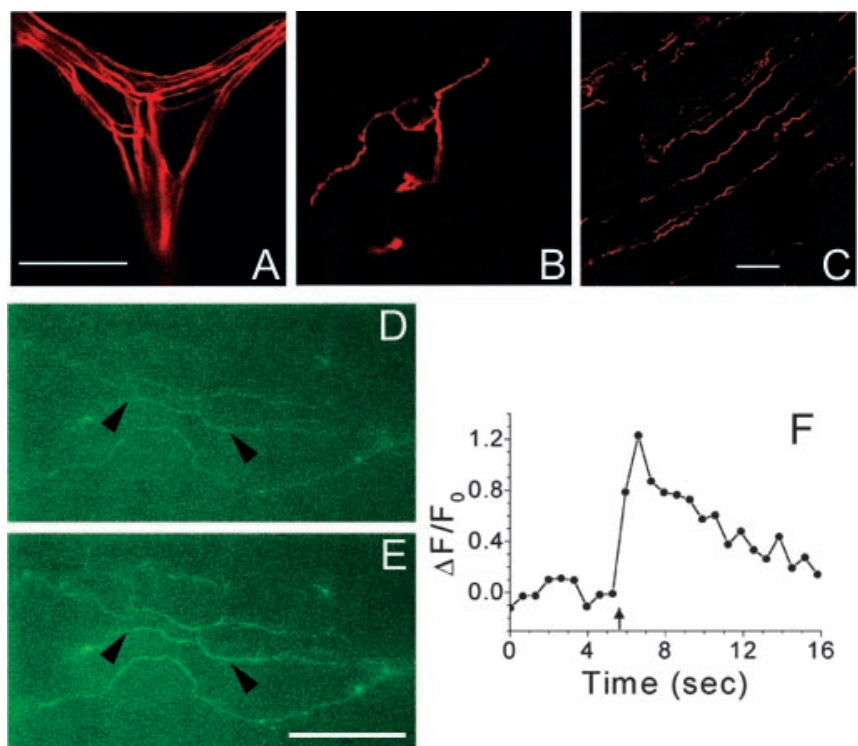

Figure 2. Fluorescent labeling of corneal nerve fibers. $A-C$, Nerve fibers were loaded with tetramethylrhodamine dextran $(10 \mathrm{kDa}) 24 \mathrm{hr}$ before confocal microscopy. $A$, Subepithelial nerve plexus lying within the stromal layer. $B$, Superficial nerve terminals $\sim 5 \mu \mathrm{m}$ below corneal surface. $C$, Nerve terminals lying deeper within the corneal epithelium. Scale bars: (in $A$ ) $A, B, 25 \mu \mathrm{m} ; C, 50 \mu \mathrm{m} . D, E$, Nerve terminals loaded with Oregon Green 488 BAPTA-1 dextran $(10 \mathrm{kDa}) 24 \mathrm{hr}$ before imaging with a cooled $C \mathrm{CD}$ camera. $D$, Nerve terminals imaged immediately before electrical stimulation. $E$, Same nerve terminals as in D imaged 1 sec after the start of a train of 10 field stimuli $(10 \mathrm{~Hz}) . F, \Delta F / F_{0}$ trace for a section (marked by arrowheads) of the middle nerve terminal seen in $D$ and $E$; arrow indicates the start of electrical stimulation. Scale bar: (in $E) D, E, 35 \mu \mathrm{m}$. For $\mathrm{Ca}^{2+}$ imaging in $D-F, 500$ msec exposures were collected at $1.67 \mathrm{~Hz}$.

OGB-1 dextran (Figs. 2, 3) and activated antidromically with a suction electrode surrounding the optic nerve and associated ciliary nerves or by electric field stimulation. $\mathrm{Ca}^{2+}$ transients in individual CNTs were reliably detected with good signal-to-noise ratios after one or more electrical stimuli (Figs. 2, 3). For individual nerve terminals, the average peak $\Delta F / F_{0}$ values for $1,5,10,20$, and 50 antidromic stimuli delivered at $10 \mathrm{~Hz}$ were $0.12 \pm 0.022$ $(n=5), 0.26 \pm 0.045(n=7), 0.42 \pm 0.080(n=7), 0.48 \pm 0.10$ $(n=7)$, and $0.60 \pm 0.12(n=7)$, respectively.

The amplitude of $\mathrm{Ca}^{2+}$ transients was steeply dependent on the number of stimuli over the range of 1-10 action potentials (Fig. $3 A, B$ ). When $>10$ stimuli were delivered, the growth in the amplitude of $\mathrm{Ca}^{2+}$ transients leveled, nearly reaching a plateau with 50 stimuli. The time-to-peak was also highly dependent on the number of stimuli delivered. As might be expected, the average peak in $\left[\mathrm{Ca}^{2+}\right]_{\mathrm{i}}$ consistently occurred immediately after the last stimulus in a train.

Lidocaine, a local anesthetic that abolishes action potentials in CNTs (Brock et al., 1998), blocked electrically evoked $\mathrm{Ca}^{2+}$ transients (Fig. 3C). In six CNTs tested, $1 \mathrm{~mm}$ lidocaine reduced the $\mathrm{Ca}^{2+}$ transients by $68 \%$ : the average peak $\Delta F / F_{0}$ values before and after lidocaine were $0.46 \pm 0.11$ and $0.14 \pm 0.013$, respectively. We suspect that the incomplete block of $\mathrm{Ca}^{2+}$ transients reflects the inability of $1 \mathrm{~mm}$ lidocaine to permeate completely through the corneal epithelium. Nonetheless, these results indicate that the $\mathrm{Ca}^{2+}$ transients observed after ciliary nerve stimulation were triggered primarily by antidromic action potentials in CNTs. In addition to lidocaine, we tested the effects of $4.1 \mu \mathrm{M}$ saxitoxin (STX) on the electrically evoked $\mathrm{Ca}^{2+}$ transients (Fig. $3 D$ ). We used STX rather than tetrodotoxin (TTX), because CNTs have TTX-resistant (TTX-R) $\mathrm{Na}^{+}$channels (Brock et al., 1998; Black and Waxman, 2002), and STX has a much higher
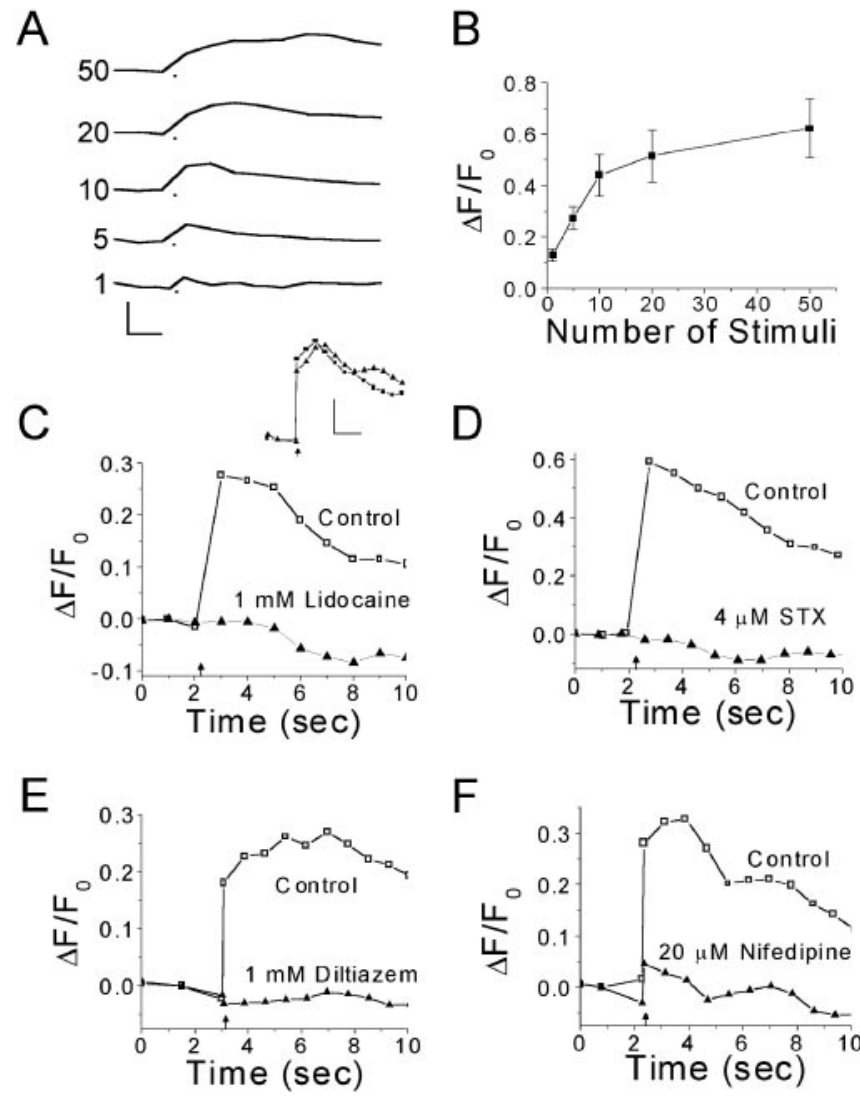

Figure 3. Effect of $\mathrm{Na}^{+}$and $\mathrm{Ca}^{2+}$ channel antagonists on $\mathrm{Ca}^{2+}$ transients evoked by electrical stimulation in corneal nerve terminals. $A$, Average $\mathrm{Ca}^{2+}$ transients evoked by electrical stimulation of the ciliary nerves. The number of stimuli $(10 \mathrm{~Hz})$ used to evoke a $\mathrm{Ca}^{2+}$ transient is indicated next to each trace. The dot below each trace marks the start of stimulation. Trace shown for one stimulus is the average of recordings from five different nerve terminals; images were 100 msec exposures captured at $2.5 \mathrm{~Hz}$. For 5-50 stimuli, records from seven separate terminals were averaged; images were $400 \mathrm{msec}$ exposures acquired at $1.4 \mathrm{~Hz}$. Calibration: $0.5 \Delta F / F_{0}, 1.0 \mathrm{sec}$. $B$, Plot of average peak $\Delta F / F_{0}$ from $A$ against number of stimuli. Note the nonlinearity in the relationship between peak $\Delta F / F_{0}$ and the number of stimuli. The plateau was not caused by indicator or detector saturation (see Discussion and Appendix). Error bars indicate \pm SEM. $C, \mathrm{Ca}^{2+}$ transients evoked in a single nerve terminal by antidromic stimulation before and after 20 min perfusion with $1 \mathrm{~mm}$ lidocaine. Inset, Control records of $\mathrm{Ca}^{2+}$ transients evoked by antidromic stimulation before (squares) and after (triangles) 20 min perfusion of Locke solution containing no drug. Calibration: $0.2 \Delta F / F_{0}, 2.0 \mathrm{sec} . D, \mathrm{Ca}^{2+}$ transients evoked in a single nerve terminal by antidromic stimulation before and after 30 min perfusion with $4.1 \mu \mathrm{M}$ STX. $E, \mathrm{Ca}^{2+}$ transients evoked in a single nerve terminal by field stimulation before and after $20 \mathrm{~min}$ perfusion with $1 \mathrm{~mm}$ diltiazem. $\mathrm{F}_{,} \mathrm{Ca}^{2+}$ transients evoked in a single nerve terminal by antidromic stimulation before and after $20 \mathrm{~min}$ perfusion with $20 \mu \mathrm{m}$ nifedipine. In $C-F$, the arrow marks the start of electrical stimulation ( 20 stimuli at $10 \mathrm{~Hz}$ ); data acquired in the absence of antagonist are represented by open symbols on traces labeled Control; data acquired in the presence of antagonist are represented by closed symbols on traces labeled with the antagonist name and concentration; 400 msec exposures were acquired at 1.4 $\mathrm{Hz}$; traces were smoothed by three-point averaging.

affinity for TTX-R Na${ }^{+}$channels than does TTX (Sivilotti et al., 1997). In these experiments, STX nearly abolished $\mathrm{Ca}^{2+}$ transients in six of seven CNTs. Inhibition was $>97 \%$ (average peak $\Delta F / F_{0}$ values before and after STX were $0.31 \pm 0.09$ and $0.004 \pm$ 0.017 , respectively). In one CNT, STX had no measurable effect.

Indirect evidence suggests that L-type VDCCs may reside in CNTs. Antagonists of L-type VDCCs attenuate corneal afferent impulse activity in response to acidic, thermal, and chemical stimuli (Pozo et al., 1992), and they have also been shown to reduce neurogenic inflammation, as well as pain responses to certain chemical stimuli (Gonzalez et al., 1993). We tested 


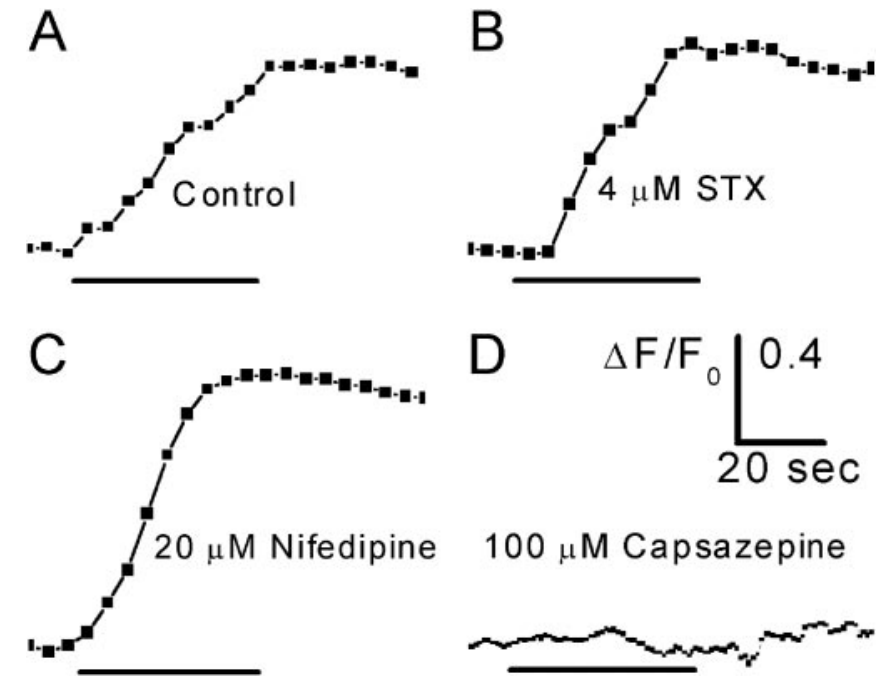

Figure 4. $\mathrm{Ca}^{2+}$ transients evoked by capsaicin in corneal nerve terminals. $A$, Response of an individual nerve terminal to $1 \mu \mathrm{m}$ capsaicin. $B$, Response of an individual nerve terminal to $1 \mu \mathrm{m}$ capsaicin after a 30 min preincubation with $4.1 \mu \mathrm{m}$ STX. C, Response of an individual nerve terminal to $1 \mu \mathrm{m}$ capsaicin after a $20 \mathrm{~min}$ preincubation with $20 \mu \mathrm{m}$ nifedipine. $D$, The response to capsaicin was completely blocked by a 35 min preincubation with $100 \mu$ m capsazepine, a VR1 antagonist. The time bar under each trace indicates the duration of capsaicin application. Images were 400 msec exposures acquired at $0.2 \mathrm{~Hz}(A-C)$ or $1.0 \mathrm{~Hz}(D)$. All traces were smoothed by three-point averaging.

whether L-type VDCCs underlie action potential-evoked $\mathrm{Ca}^{2+}$ transients by bath applying $1 \mathrm{~mm}$ diltiazem or $20 \mu \mathrm{M}$ nifedipine, nonspecific and specific antagonists of L-type VDCCs, respectively (Fig. $3 E, F$ ). Diltiazem reduced impulse-evoked $\mathrm{Ca}^{2+}$ transients by $97 \%$ in all five CNTs in which $\mathrm{Ca}^{2+}$ transients were evoked by field stimulation (20 stimuli at $10 \mathrm{~Hz}$ ). The average peak $\Delta F / F_{0}$ was $0.26 \pm 0.033$ in the absence of diltiazem and $0.002 \pm 0.001$ in the presence of diltiazem. Nifedipine $(20 \mu \mathrm{M})$ reduced by $82 \%$ the amplitudes of $\mathrm{Ca}^{2+}$ transients evoked by 20 antidromic impulses ( $10 \mathrm{~Hz}$; three of three CNTs). Average peak $\Delta F / F_{0}$ values before and after nifedipine were $0.65 \pm 0.054$ and $0.10 \pm 0.003$, respectively.

Most CNTs respond strongly to capsaicin, which suggests that they are nociceptive (Belmonte and Gallar, 1996). Capsaicin is an agonist at the vanilloid receptor 1 (VR1), which is permeable to cations, including $\mathrm{Ca}^{2+}$ (Caterina et al., 1997). VR1 has been shown to be expressed on nerve fibers of the cornea (Guo et al., 1999). Capsaicin $(1 \mu \mathrm{M})$ applied directly to sections of isolated corneas evoked robust $\mathrm{Ca}^{2+}$ transients (10 of $10 \mathrm{CNTs}$ ) (Fig. 4). The VR1 antagonist capsazepine $(100 \mu \mathrm{M})$ completely blocked capsaicinevoked $\mathrm{Ca}^{2+}$ transients in three CNTs tested (Fig. 4). In contrast, preincubation with $20 \mu \mathrm{M}$ nifedipine or $4.1 \mu \mathrm{M}$ STX did not attenuate $\mathrm{Ca}^{2+}$ transients evoked by $1 \mu \mathrm{M}$ capsaicin (Fig. $4 B, C$ ). Average peak $\Delta F / F_{0}$ values without and with nifedipine were $0.48 \pm 0.094$ $(n=10)$ and $0.44 \pm 0.24(n=5)$, respectively. Average peak $\Delta F / F_{0}$ values without and with STX were $0.48 \pm 0.094(n=10)$ and $0.90 \pm$ $0.17(n=7)$, respectively. The reason for significant augmentation of the capsaicin response by STX remains to be explored.

\section{Discussion}

The present study was designed to investigate whether activation of PSNTs in situ elicits increases in nerve terminal $\left[\mathrm{Ca}^{2+}\right]_{i}$. The cornea is an ideal tissue for this investigation, because it is transparent and is innervated almost exclusively by sensory $\mathrm{A} \delta$ and $\mathrm{C}$ fibers terminating as free nerve endings in the corneal epithelium (Rozsa and Beuerman, 1982; MacIver and Tanelian, 1993). After staining CNTs in vivo with the fluorescent $\mathrm{Ca}^{2+}$ indicator Oregon Green 488 BAPTA-1 dextran, we could readily visualize CNTs in vitro with fluorescence microscopy (Figs. 2, 3) and measure changes in their $\left[\mathrm{Ca}^{2+}\right]_{\mathrm{i}}$ evoked by action potentials or the chemical irritant capsaicin. These results demonstrate, for the first time, that electrical or chemical stimulation of a PSNT changes its $\left[\mathrm{Ca}^{2+}\right]_{\mathrm{i}}$. Previous studies have suggested that L-type VDCCs may play a role in CNT physiology (Pozo et al., 1992; Gonzalez et al., 1993). Our observation that L-type $\mathrm{Ca}^{2+}$ channel antagonists blocked impulse-evoked $\mathrm{Ca}^{2+}$ transients provide direct evidence of $\mathrm{Ca}^{2+}$ influx through VDCCs into CNTs.

The influx of $\mathrm{Ca}^{2+}$ in PSNTs may serve many functions. It could support the release of SP and CGRP to provide trophic influences on target tissues and mediate neurogenic inflammation (Maggi, 1991; White, 1997). The type of VDCC required for release of SP appears to depend on the nature of the stimulus. In rat dorsal root ganglion neurons, for example, activation of $\mathrm{N}$-type VDCCs is necessary for SP release after stimulation with bradykinin; however, activation of L-type VDCCs is required for SP release evoked by $\mathrm{KCl}$ depolarization (Evans et al., 1996). Although the majority of CNTs contain SP and CGRP (Marfurt, 2000), the types of $\mathrm{Ca}^{2+}$ channels that are necessary for neuropeptide release remain to be determined.

Influx of $\mathrm{Ca}^{2+}$ into PSNTs may also be necessary for mechanical transduction (Sullivan et al., 1997), regulation of membrane excitability (Undem et al., 2003), and sensitization to inflammatory stimuli (Chen et al., 1997b; Shu and Mendell, 2001). The existence of L-type VDCCs in CNTs provides one pathway for $\mathrm{Ca}^{2+}$ to enter nerve terminals to support these processes. Another pathway for $\mathrm{Ca}^{2+}$ entry into PSNTs is via ligand-gated channels. Capsaicin, the pungent essence of chili peppers, causes excitation of CNTs that is prevented by pretreatment with capsazepine, a VR1 antagonist (Chen et al., 1997a). We observed that capsaicin evoked $\mathrm{Ca}^{2+}$ transients in a capsazepine-sensitive manner. The $\mathrm{Ca}^{2+}$ transients evoked by capsaicin could, in theory, arise from $\mathrm{Ca}^{2+}$ influx through multiple pathways. VR1 is a nonselective cation channel that is permeable to $\mathrm{Na}^{+}$as well as $\mathrm{Ca}^{2+}$. Thus, $\mathrm{Ca}^{2+}$ could enter the CNTs directly through the VR1. Because capsaicin can trigger membrane depolarization and action potential activity, part of the capsaicin-evoked $\mathrm{Ca}^{2+}$ transient could have been the result of $\mathrm{Ca}^{2+}$ entering CNTs through VDCCs. However, nifedipine did not affect capsaicin responses. This suggests that the $\mathrm{Ca}^{2+}$ transients we observed were the result of $\mathrm{Ca}^{2+}$ influx through the VR1 directly. STX also did not attenuate capsaicin responses. This suggests that $\mathrm{Na}^{+}$channel activity is not essential for the capsaicin-evoked $\mathrm{Ca}^{2+}$ transient and that the capsaicin-evoked $\mathrm{Ca}^{2+}$ transient does not depend on propagated action potentials. It is interesting to note that, in rat dorsal root ganglion cells, $\mathrm{Ca}^{2+}$ influx through the VR1 alone is sufficient for SP release, independent of VDCC activation (Evans et al., 1996).

The balance of $\mathrm{Ca}^{2+}$ influx and clearance mechanisms appears to be dynamically regulated in CNTs. We observed that the amplitudes of $\mathrm{Ca}^{2+}$ transients approach a plateau after a few tens of stimuli (Fig. 3). The leveling of the amplitudes of $\mathrm{Ca}^{2+}$ transients with increasing number of action potentials was not caused by saturation of the indicator or the CCD camera. In the Appendix, we present a mathematical treatment of the dependence of $\Delta F / F_{0}$ values on changes in $\left[\mathrm{Ca}^{2+}\right]_{\mathrm{i}}$. The analysis suggests that indicator saturation is not a confounding factor in our measurements. This was empirically verified by the observation that larger $\mathrm{Ca}^{2+}$ transients with faster kinetics of rise could be evoked when the same number of stimuli was delivered at twice the fre- 
quency ( $n=3$; data not shown). Furthermore, we also observed that the capsaicin-induced $\mathrm{Ca}^{2+}$ transients were significantly larger than the electrically evoked $\mathrm{Ca}^{2+}$ transients on the plateau of the $\Delta F / F_{0}$ versus number of stimuli curve $(n=7$; data not shown). This gives additional evidence that the plateau is physiological and not an artifact of indicator saturation. Thus, CNTs appear to have the capacity to extrude free $\mathrm{Ca}^{2+}$ at rates comparable with that of action potential-evoked influx. The identities of these clearance mechanisms and the manner in which they are regulated are still unknown and will be the focus of future studies.

In summary, PSNT physiology is dependent on intracellular $\left[\mathrm{Ca}^{2+}\right]$ and, therefore, on the mechanisms that underlie intracellular $\left[\mathrm{Ca}^{2+}\right]$ homeostasis. The ability to image $\mathrm{Ca}^{2+}$ transients in individual nerve terminals now opens a new window onto the cellular mechanisms underlying peripheral nerve terminal physiology and pathophysiology.

\section{Appendix}

Under conditions of low optical density, the fluorescence intensity $(F)$ of a sample is linearly dependent on the fluorophore concentration $(C): F=s Q \epsilon C$, where $Q$ is the quantum efficiency of fluorescence emission, $\epsilon$ is the molar absorptivity of the fluorophore at the excitation wavelength, and $s$ is an instrumentdependent proportionality factor that includes the excitation light intensity, the detector sensitivity at the emission wavelength, and the sample thickness. OGB-1 dextran is an intensiometric indicator whose $\mathrm{Ca}^{2+}$-free and $\mathrm{Ca}^{2+}$-bound forms have the same excitation wavelength and also fluoresce at the same emission wavelength but differ in their molar absorptivity and fluorescence quantum efficiency. At any arbitrary $\left[\mathrm{Ca}^{2+}\right]_{\mathrm{i}}$, the total fluorescence intensity of the sample contains contributions from both $\mathrm{Ca}^{2+}$-free and $\mathrm{Ca}^{2+}$-bound forms of the indicator: $F=$ $s\left[Q_{f} \epsilon_{f} C_{f}+Q_{b} \epsilon_{b} C_{b}\right]$, where subscripts $f$ and $b$ refer to the $\mathrm{Ca}^{2+}$ free and $\mathrm{Ca}^{2+}$-bound forms, respectively. The expression may be rewritten as $F=s C_{\mathrm{T}}\left[Q_{f} \epsilon_{f}\left(1-\alpha_{b}\right)+Q_{b} \epsilon_{b} \alpha_{b}\right]$, where $C_{\mathrm{T}}$ is the total indicator concentration, and the fraction of indicator that is $\mathrm{Ca}^{2+}$-bound is $\alpha_{b}=\left[\mathrm{Ca}^{2+}\right] /\left(\left[\mathrm{Ca}^{2+}\right]+K_{\mathrm{d}}\right)$, with $K_{\mathrm{d}}$ being the $\mathrm{Ca}^{2+}$ dissociation constant of the indicator. $F_{0}$ is measured at resting $\left[\mathrm{Ca}^{2+}\right]$ (at $\left.\alpha_{b \text {,rest }}\right)$, whereas $F_{\max }$ occurs at saturating levels of $\left[\mathrm{Ca}^{2+}\right]\left(\right.$ when $\left.\alpha_{b}=1\right)$. Because $F_{\max } / F_{0}=\left(F_{0}+\Delta F_{\max }\right) / F_{0}=$ $1+\left(\Delta F / F_{0}\right)_{\max }$, the maximum $\Delta F / F_{0}$ is given by $\left(\Delta F / F_{0}\right)_{\max }=$ $\left[\left(1-\alpha_{b, \text { rest }}\right) Q_{f} \epsilon_{f} f Q_{b} \epsilon_{b}+\alpha_{b, \text { rest }}\right]^{-1}-1$. For OGB-1 dextran, knowing that $\epsilon_{f}=76,000 \mathrm{M}^{-1} \cdot \mathrm{cm}^{-1}, \epsilon_{b}=78,000 \mathrm{M}^{-1} \cdot \mathrm{cm}^{-1}$, $Q_{f}=0.05, Q_{b}=0.70$, and $K_{\mathrm{d}}=265 \mathrm{nM}$, we can calculate $(\Delta F /$ $\left.F_{0}\right)_{\max }$ as a function of resting $\left[\mathrm{Ca}^{2+}\right]$. Thus, for reasonable resting $\left[\mathrm{Ca}^{2+}\right]$ values of 50,75 , and $100 \mathrm{nM}$, the corresponding $(\Delta F /$ $\left.F_{0}\right)_{\max }$ values are $3.6,2.6$, and 2.1 , respectively. That our measured $\Delta F / F_{0}$ values were always much lower than these estimates suggests that our measurements were not distorted by indicator saturation.

\section{References}

Belmonte C, Gallar J (1996) Corneal nociceptors. In: Neurobiology of nociceptors (Belmonte C, Cervero F, eds), pp 146-183. New York: Oxford UP.
Black JA, Waxman SG (2002) Molecular identities of two tetrodotoxinresistant sodium channels in corneal axons. Exp Eye Res 75:193-199.

Brock JA, Mclachlan EM, Belmonte C (1998) Tetrodotoxin-resistant impulses in single nociceptor nerve terminals in guinea-pig cornea. J Physiol (Lond) 512:211-217.

Caterina MJ, Schumacher MA, Tominaga M, Rosen TA, Levine JD, Julius D (1997) The capsaicin receptor: a heat-activated ion channel in the pain pathway. Nature 398:816-824.

Chen X, Belmonte C, Rang HP (1997a) Capsaicin and carbon dioxide act by distinct mechanisms on sensory nerve terminals in the cat cornea. Pain 70:23-29.

Chen X, Gallar J, Belmonte C (1997b) Reduction by antiinflammatory drugs of the response of corneal sensory nerve fibers to chemical irritation. Invest Ophthalmol Vis Sci 38:1944-1953.

Evans AR, Nicol GD, Vasko MR (1996) Differential regulation of evoked peptide release by voltage-sensitive calcium channels in the rat sensory neurons. Brain Res 712:265-273.

Gonzalez GG, Garcia de La Rubia P, Gallar J, Belmonte C (1993) Reduction of capsaicin-induced ocular pain and neurogenic inflammation by calcium antagonists. Invest Ophthalmol Vis Sci 34:3329-3335.

Guo A, Vulchanova L, Wang J, Li X, Elde R (1999) Immunocytochemical localization of the vanilloid receptor 1 (VR1): relationship to neuropeptides, the $\mathrm{P}_{2} \mathrm{X}_{3}$ purinoceptor and IB4 binding sites. Eur J Neurosci 11:946-958.

Harris LW, Purves D (1989) Rapid remodeling of sensory endings in the cornea of living mice. J Neurosci 9:2210-2214.

Jones MA, Marfurt C (1998) Peptidergic innervation of the rat cornea. Exp Eye Res 66:421-435.

MacIver MB, Tanelian DL (1993) Structural and functional specialization of $\mathrm{A} \delta$ and $\mathrm{C}$ fiber free nerve endings innervating rabbit corneal epithelium. J Neurosci 13:4511-4524.

Maggi CA (1991) The pharmacology of the efferent function of sensory nerves. J Auton Pharmacol 11:173-208.

Marfurt CF (2000) Nervous control of the cornea. In: Nervous control of the eye (Burnstock G, Sillito AM, eds), pp 41-92. Amsterdam: Harwood Academic.

Pozo MA, Gallego R, Gallar J, Belmonte C (1992) Blockade by calcium antagonists of chemical excitation and sensitization of polymodal nociceptors in the cat's cornea. J Physiol (Lond) 450:179-189.

Rozsa AJ, Beuerman RW (1982) Density and organization of free nerve endings in the corneal epithelium of the rabbit. Pain 14:105-120.

Shu X, Mendell LM (2001) Acute sensitization by NGF of the response of smalldiameter sensory neurons to capsaicin. J Neurophysiol 86:2931-2938.

Sivilotti L, Okuse K, Akopian AN, Moss S, Wood JN (1997) A single serine residue confers tetrodotoxin insensitivity on the rat sensory-neuronspecific sodium channel SNS. FEBS Lett 409:49-52.

Sullivan MJ, Sharma RV, Wachtel RE, Chapleau MW, Waite LJ, Bhalla RC, Abboud FM (1997) Non-voltage-gated $\mathrm{Ca}^{2+}$ influx through mechanosensitive ion channels in aortic baroreceptor neurons. Circ Res 80:861-867.

Undem BJ, Oh EJ, Lancaster E, Weinreich D (2003) Effect of extracellular calcium on excitability of guinea pig airway vagal afferent nerves. J Neurophysiol 89:1196-1204.

White DM (1997) Release of substance P from peripheral sensory nerve terminals. J Peripher Nerv Syst 2:191-201.

Whitear EC (1960) An electron microscope study of the cornea in mice, with special reference to the innervation. J Anat 94:387-409.

Zander E, Weddell G (1951) Observations of the innervation of the cornea. J Anat 85:68-69. 